\title{
Abnormal anxiety- and depression-like behaviors in mice lacking both central serotonergic neurons and pancreatic islet cells
}

\author{
Yun-Fang Jia ${ }^{1,2 \dagger}$, Ning-Ning Song ${ }^{3,4}{ }^{\dagger}$, Rong-Rong Mao ${ }^{1,2}$, Jin-Nan Li, ${ }^{1,2}$, Qiong Zhang ${ }^{3,4}$, \\ Ying Huang ${ }^{3,4}$, Lei Zhang ${ }^{3,4}$, Hui-Li Han ${ }^{1,2}$, Yu-Qiang Ding ${ }^{3,4}$ and Lin Xu ${ }^{1,2}$ *
}

\author{
Key Laboratory of Animal Models and Human Disease Mechanisms of Chinese Academy of Sciences and Yunnan Province, and KIZ/CUHK Joint Laboratory of \\ Bioresources and Molecular Research in Common Disease, and Laboratory of Learning and Memory, Kunming Institute of Zoology, Chinese Academy of \\ Sciences, Kunming, China \\ ${ }^{2}$ Kunming College of Life Science, University of Chinese Academy of Sciences, Beijing, China \\ ${ }^{3}$ Key Laboratory of Arrhythmias, Ministry of Education of China, East Hospital, Tongji University School of Medicine, Shanghai, China \\ ${ }^{4}$ Department of Anatomy and Neurobiology, Tongji University School of Medicine, Shanghai, China
}

\section{Edited by:}

Gal Richter-Levin, University of

Haifa, Israel

Reviewed by:

Gregg Stanwood, Vanderbilt

University, USA

Eero Vasar, University of Tartu, Estonia

*Correspondence:

Yu-Qiang Ding, Department of Anatomy and Neurobiology, Tongji

University School of Medicine, 1239 Siping Road, Shanghai 200092,

China

e-mail: dingyuqiang@vip.163.com; Lin Xu, Laboratory of Learning and Memory, Kunming Institute of Zoology, Chinese Academy of Sciences, 32 East Jiao-Chang Road, Kunming 650223, China

e-mail: Ixu@vip.163.com

${ }^{+}$These authors have contributed equally to this work.
Dysfunction of central serotonin (5-HT) system has been proposed to be one of the underlying mechanisms for anxiety and depression, and the association of diabetes mellitus and psychiatric disorders has been noticed by the high prevalence of anxiety/depression in patients with diabetes mellitus. This promoted us to examine these behaviors in central 5-HT-deficient mice and those also suffering with diabetes mellitus. Mice lacking either 5-HT or central serotonergic neurons were generated by conditional deletion of $T p h 2$ or $L m \times 1 b$ respectively. Simultaneous depletion of both central serotonergic neurons and pancreatic islet cells was achieved by administration of diphtheria toxin (DT) in Pet1-Cre;Rosa26-DT receptor (DTR) mice. The central 5-HT-deficient mice showed reduced anxiety-like behaviors as they spent more time in and entered more often into the light box in the light/dark box test compared with controls; similar results were observed in the elevated plus maze test. However, they displayed no differences in the immobility time of the forced swimming and tail suspension tests suggesting normal depression-like behaviors in central 5-HT-deficient mice. As expected, DT-treated Pet1-Cre;Rosa26-DTR mice lacking both central serotonergic neurons and pancreatic islet endocrine cells exhibited several classic diabetic symptoms. Interestingly, they displayed increased anxiety-like behaviors but reduced immobility time in the forced swimming and tail suspension tests. Furthermore, the hippocampal neurogenesis was dramatically enhanced in these mice. These results suggest that the deficiency of central 5-HT may not be sufficient to induce anxiety/depression-like behaviors in mice, and the enhanced hippocampal neurogenesis may contribute to the altered depression-like behaviors in the 5-HT-deficient mice with diabetes. Our current investigation provides understanding the relationship between diabetes mellitus and psychiatric disorders.

Keywords: diabetes mellitus, anxiety, depression, serotonin, Pet1, adult neurogenesis

\section{INTRODUCTION}

The central serotonin (5-HT) system is known to be involved in emotion, learning and memory (Barnes and Sharp, 1999; Duman and Voleti, 2012), and 5-HT deficiency in the brain is believed to be a major causative factor in anxiety and depression (Brigitta, 2002; Leonardo and Hen, 2006). Selective 5-HT reuptake inhibitors (SSRIs), which can promote monoamine system functions, attenuate anxiety-like behaviors (Graeff et al., 1996) and also produce certain beneficial effects in patients with depression (Artigas et al., 1996; Blier and Ward, 2003). They are currently the most commonly prescribed class of antidepressants (Santarelli et al., 2003), although the exact molecular mechanisms behind their antidepressant effects are not fully understood. The use of SSRIs may help to alleviate the symptoms of depression by promoting adult neurogenesis in the hippocampus (Malberg et al., 2000; Santarelli et al., 2003).

The global prevalence of diabetes mellitus has been steadily increasing over the past few decades (Alberti et al., 1998; Wild et al., 2004). The diabetes type I is caused by the destruction of pancreatic islet endocrine cells (Butler et al., 2003), whose normal function is to secrete hormones that regulate blood glucose homeostasis, such as insulin (Lenoir et al., 2011). The typical symptoms of diabetes include polyuria, polyphagia and polydipsia as well as the elevation of blood glucose level (Alberti et al., 1998; Cooke and Plotnick, 2008). Despite the symptoms of diabetes mellitus and psychiatric disorders (e.g., anxiety and 
depression) are very much non-overlapping, these two disorders are somehow co-occurred (Ciechanowski et al., 2000; Anderson et al., 2001). For example, the prevalence of anxiety/depression is 2-3 times higher in patients with diabetes mellitus compared with the general population (Popkin et al., 1988; Blanz et al., 1993), and this observation has sparked the hypothesis that an increased risk of developing anxiety and depression may be a complication of diabetes mellitus. Some clinical studies have also shown that anxiety/depression may be a risk factor for diabetic complications as well as increased morbidity and mortality from diabetes mellitus (Anderson et al., 2001).

Our previous studies have reported that transcription factor $L m \times 1 b$ is required for the development of central serotonergic neuron (Ding et al., 2003), and conditional deletion of this gene results in the loss of serotonergic neurons therefore offering a central 5-HT-deficient mouse model (Dai et al., 2008). Tryptophan hydroxylase (Tph2) is the key enzyme for 5-HT synthesis in the brain (Zhang et al., 2004), and specific deletion of Tph2 leads to the central 5-HT deficiency without affecting the survival of the serotonergic neurons (Savelieva et al., 2008; Kriegebaum et al., 2010). The prototypical serotonergic transcription factor Pet1 is expressed in both central serotonergic neurons and pancreatic islet cells (Hendricks et al., 1999, 2003; Ohta et al., 2011), and Pet1-driven Cre expression was used to simultaneously deplete these two kinds of cells in Pet1-Cre;Rosa26-diphtheria toxin receptor (DTR) mice in adulthood. The aim of the present study was to examine whether central 5-HT deficiency results in abnormal anxiety- and depression-like behaviors, and to explore the possible involvement of diabetes mellitus in these behaviors and the underlying mechanisms.

\section{MATERIALS AND METHODS MICE}

Mice lacking central serotonergic neurons (Pet1-Cre; $L m \times 1 b^{\text {flox/flox }}$ ) were generated by crossing Pet1-Cre mice to flox $L m x 1 b$ mice (hereafter referred to as PC/Lmxlb) as reported in our previous study (Dai et al., 2008). The other central 5-HT-deficient mice (Pet1-Cre;Tph2 $2^{\text {flox/flox }}$; referred to as $\mathrm{PC} / \mathrm{Tph} 2)$ used in this study were obtained by crossing Pet1-Cre mice to flox Tph2 mice as described in our previous report also, which contained central serotonergic neurons but failed to synthesize 5-HT (Kriegebaum et al., 2010). To simultaneously deplete both the central serotonergic neurons and pancreatic islet cells, Pet1-Cre;Rosa26-DTR (referred to as PC/DTR) mice were generated by crossing Rosa26-DTR mice (Buch et al., 2005) to Pet1-Cre mice. In addition, Pet1-Cre/Rosa26-LacZ mice were generated by crossing Rosa26-LacZ mice (Soriano, 1999) to Pet1Cre mice; this was used to examine the Cre activity in the pancreas and brain. Furthermore, Pomc-GFP mice (Overstreet et al., 2004) were crossed with PC/DTR mice to obtain PC/DTR/Pomc-GFP mice, which were used to visualize immature neurons in the subgranular zone (SGZ) of the dentate gyrus.

In the set of experiment for depleting central serotonergic neurons and pancreatic islet cells, DT was intraperitoneally injected once daily for 2 days (20 ng/g body weight; Sigma) in PC/DTR or PC/DTR/Pomc-GFP mice and control mice. Behavioral tests and immunostaining analysis were performed 3-4 weeks after DT injection. Animals were group-housed (4-5 mice per cage) in a thermo-regulated environment $\left(22-24^{\circ} \mathrm{C}\right)$ with ad libitum access to water and food, and on a 12-h light/dark cycle. All animal care and experimental protocols were approved by the Animal Research Committees of the Kunming Institute of Zoology, Chinese Academy of Sciences and the Tongji University School of Medicine, China.

\section{X-GAL STAINING}

$\mathrm{X}$-gal staining was used to detect Cre recombinase activity in Pet1-Cre mice. Two-week old Pet1-Cre;Rosa26 mice were deeply anesthetized, then their pancreas and brain were dissected in cold 0.01 M phosphate buffered saline (PBS; pH 7.4), fixed in $4 \%$ paraformaldehyde in PBS for $2 \mathrm{~h}$ at $4^{\circ} \mathrm{C}$, rinsed briefly in PBS and cryoprotected with $30 \%$ sucrose in PBS overnight. Twenty- $\mu \mathrm{m}$ thick sections were then cut with a cryostat. The sections were stained with $\mathrm{X}$-gal solution containing $1 \mathrm{mg} / \mathrm{ml}$ $\mathrm{X}$-gal, $2 \mathrm{mM} \mathrm{MgCl}_{2}, 5 \mathrm{mM} \mathrm{K}_{3} \mathrm{Fe}(\mathrm{CN})_{6}$ and $5 \mathrm{mM} \mathrm{K}_{4} \mathrm{Fe}(\mathrm{CN})_{6}$ for $10-16 \mathrm{~h}$ at $37^{\circ} \mathrm{C}$, and then slightly counterstained with neutral red.

\section{IMMUNOHISTOCHEMISTRY, BROMODEOXYURIDINE (BrdU) LABELING AND IN SITU HYBRIDIZATION}

After perfusing with 4\% paraformaldehyde, brains were removed and post-fixed overnight. Forty- $\mu \mathrm{m}$ brain sections were cut and incubated with mouse anti-bromodeoxyuridine (BrdU) (1:300; Calbiochem) or goat anti-NeuroD (1:400; Santa Cruz) primary antibody at $4^{\circ} \mathrm{C}$ overnight, followed by incubation with the appropriate biotinylated secondary antibody (1:500; Vector) for $3 \mathrm{~h}$ and Cy3-conjugated streptavidin (1:1000; Jackson ImmunoResearch) for $1 \mathrm{~h}$ at room temperature. For BrdU pulse labeling, mice were injected with BrdU (50 mg/kg body weight) four times at 2-h intervals, and then sacrificed for analysis 2 $\mathrm{h}$ after the last injection. Prepared sections were treated with $0.01 \mathrm{M}$ citrate buffer at $95^{\circ} \mathrm{C}$ for $5 \mathrm{~min}$, then incubated in 2 $\mathrm{N} \mathrm{HCl}$ at $37^{\circ} \mathrm{C}$ for $20 \mathrm{~min}$ and in $0.1 \mathrm{M}$ sodium borate for 10 min, and finally washed in PBS. The treated sections were then immunostained with mouse anti-BrdU antibody as described above. In situ hybridization for detection of Pet1 mRNA expression was performed as reported in our previous study (Song et al., 2011). Images were captured using a Nikon epifluorescence microscope (Eclipse 80i) or a confocal microscope (TCS SP5, Leica). Cell counts in the dorsal raphe nucleus and hippocampal SGZ were performed in every sixth section from each animal. As the factor of volumes of the counted brain regions were not included, our counting method may lead to an overestimation or underestimation of the real number of serotonergic neurons in the raphe nucleus and new-born neurons in the dentate gyrus.

\section{DIABETES RELATED EXAMINATION}

Body weight was measured manually at the beginning of all experiments. Blood glucose level was measured from the mice tail vein blood using the glucometer (ONE TOUCH Ultra Glucometer, Johnson \& Johnson Medical [China] CO., Ltd.) after 3-h fasting. The quantities of food and water intake were assessed by a metabolic cage and the monitoring software (Panlab Harvard). Diptheria toxin injected control mice were individually placed 
in one cage and allowed free access to food and water during a 24-h period, and the quantities were recorded at each hour; DT-injected PC/DTR mice were treated in the same way. The data of food and water intake were recorded by the monitoring software.

\section{BEHAVIORAL OBSERVATION}

Adult (3-5 months old) male mice were used in the following behavioral observation. Physiological cycle in adult female mice may cause the instability of some hormones (e.g., estrogen), and this may influence the behavioral performances and therefore complicate dissecting the relationship between the central 5-HT deficiency and behavioral studies. The experiments were performed during 9:00 am to 17:00 pm, and animal behaviors were videotaped. It should be noted that the behavioral data acquisition and analysis were performed by a double-blind manner; people performed these were blind to genotypes. Animals were habituated in the test room for $2 \mathrm{~h}$ before starting the experiments.

In this study, multiple mouse lines were used, and they were generated by crossing two lines of mice thus having a mixed genetic background. Behavioral performances are different in different mouse stains, and the genetic background of control mice was well controlled in the following ways. First, to minimize the contribution of strain differences, the mice lines used in this study have been intercrossed by sister-brother mating over seven generations to get a congenetic background. Second, in each set of behavioral observations, comparison was made only between gene-modified mice (i.e., PC/Lmx1b, PC/Tph2 and PC/DTR) and wild type mice (controls) from the same litters, which should have the same mixed genetic background.

\section{LIGHT/DARK BOX TEST}

We used a light/dark box (ENV-510 test environment) that were divided into two equally sized compartments $(13.5 \times 27 \times$ $20.3 \mathrm{~cm}$ ) together with the activity monitoring software (Activity Monitor; Med Associates) to evaluate the anxiety levels. Mice were placed in the central light box facing the dark box and were allowed to freely explore for $5 \mathrm{~min}$. The amount of time spent in the light box and the frequency of transitions between the light and dark boxes were recorded. The data of PC/Tph2 mice were recorded by an experienced observer by means of a video/computer system, while the data of PC/DTR mice were measured by the activity monitoring software (Med Associates).

\section{ELEVATED PLUS MAZE}

Elevated plus maze (Med Associates) also was used to test anxietylike behaviors (Lister, 1987; Weisstaub et al., 2006), and the platform was elevated $74 \mathrm{~cm}$ above the floor, which consisted of two open $(35 \times 6 \mathrm{~cm})$ and two closed $(35 \times 6 \times 22 \mathrm{~cm})$ arms and a connecting central zone $(6 \times 6 \mathrm{~cm})$. Mice were placed on the central platform facing an open arm and were allowed to freely explore the maze for $5 \mathrm{~min}$. The amount of time spent in the open arms and the frequency of transitions between the open and closed arms were recorded. The data of $\mathrm{PC} / \mathrm{Tph} 2$ mice were measured by an experienced observer who was blind to genotypes by means of a video/computer system, while the data of PC/DTR mice were recorded by the monitoring software.

\section{FORCED SWIMMING TEST}

This test was used to assess behavioral despair in mice, which is often used to approximate some aspects of depression in humans (Porsolt, 2000; Nestler et al., 2002) as described previously (Porsolt et al., 1977; David et al., 2003; Tian et al., 2011). The apparatus consisted of a glass cylinder $(24 \mathrm{~cm}$ height, 16 $\mathrm{cm}$ diameter) that was filled with water to a depth $18 \mathrm{~cm}$ and maintained at $25 \pm 1^{\circ} \mathrm{C}$. Mice were forced to swim $6 \mathrm{~min}$, and the time spent immobile during the last $4 \mathrm{~min}$ was recorded by an experienced observer who was blind to genotype. They were considered immobile when they stopped struggling, only moved slightly and occasionally to keep their nose above the water surface.

\section{TAIL SUSPENSION TEST}

Time spent immobile in this test was also used to measure behavioral despair (Steru et al., 1985; Castagne et al., 2011). Mice were suspended by the tail from a vertical stainless steel hook (distance from floor: $20 \mathrm{~cm}$ ) using adhesive tape (distance from tip of tail: $2 \mathrm{~cm}$ ). The immobility time was recorded by the activity monitoring software (Med Associates, Tail suspension system) during suspended the mice $6 \mathrm{~min}$. They were considered immobile when they hung passively without any movement.

\section{OPEN FIELD TEST}

The ENV-510 test environment equipped with infrared beams and Activity Monitor (Med Associates) were used to evaluate motor activity in the open field test. Mice were placed in a Plexiglas box $(27 \times 27 \times 20.3 \mathrm{~cm})$ to freely explore the chamber for the duration of the test session and the locomotor activity was monitored over a 30-min period, and the data were recorded by each beam break as one unit of exploratory activity using the activity monitoring software (Med Associates).

\section{ROTAROD TEST}

Mice were placed on the rotating rod and the latency to fall was measured with a 4-40 rpm accelerating speed during $5 \mathrm{~min}$ (Panlab Harvard). Each mouse was tested three times at 1-h intervals after habituating 2 min each time, and was placed on the rod for a maximum of $15 \mathrm{~min}$ per trial.

\section{STATISTICAL ANALYSIS}

All data were expressed as mean \pm SEM. Comparison between two groups was conducted by unpaired Student's $t$-test, the food and water intake tests were analyzed by using a repeated measure ANOVA followed by the Tukey Honestly Significantly Different (HSD) test. Differences were considered statistically significant if $p<0.05$.

\section{RESULTS}

\section{ABNORMAL BEHAVIORS IN THE CENTRAL 5-HT-DEFICIENT MICE}

We first detected the anxiety- and depression-like behaviors in PC/Tph2 mice (Pet1-Cre;Tph2 $2^{\text {flox/flox }}$ ) in which Tph2, the key enzyme for 5-HT synthesis, was deleted in the central serotonergic neurons as reported previously (Kriegebaum et al., 2010). 
Inactivation of $T p h 2$ did not affect the survival of serotonergic neurons in the brain as revealed by the expression of Pet1 in $\mathrm{PC} / \mathrm{Tph} 2$ mice (Figures 1A,B). The spontaneous locomotor activity shown by the travelled distance in the open field was not different between the PC/Tph2 and control mice (Figure 1C). In the light/dark box test, PC/Tph2 mice displayed more time in the light box (Figure 1D), and more times of entries into the light box compared with controls (Figure 1E). Similar results were obtained in the elevated plus maze test, shown by spending more time in the open arms (Figure 1F) and more times of entries into the open arms in PC/Tph2 mice compared with controls (Figure 1G). On the other hand, in the forced swimming (Figure $\mathbf{1 H}$ ) and tail suspension tests (Figure 1I), no significant differences were detected in the immobility time between the PC/Tph2 and control mice. These results suggest that the level of anxiety-like behaviors may be decreased but that of depression-like behaviors is likely unchanged in PC/Tph2 mice.

The unchanged depression-like and decreased anxiety-like behaviors in PC/Tph2 mice are somehow inconsistent with the monoamine deficiency hypothesis of depression which is supported by the anti-depressive effect of SSRIs. To further confirm this, we set out to examine these behaviors in PC/Lmxlb (Pet1Cre; $L m \times 1 b^{\text {flox/flox }}$ ) mice lacking the central serotonergic neurons (Dai et al., 2008). Reduced anxiety-like behaviors revealed by both the elevated plus maze and novelty suppressed feeding tests has been published in our previous study (Dai et al., 2008). Here, we found that in the forced swimming and tail suspension tests, PC/Lmx1b mice behaved similarly as PC/Tph2 mice; the immobility time was not different from control mice (Figures 1J,K). Taken together, these results suggest the possibility that 5-HT deficiency in the brain may not be sufficient to alter the depressionlike behaviors but may lead to a reduced anxiety level in mice.

\section{PET1-EXPRESSING CELLS ARE LOCATED IN BOTH PANCREATIC ISLET AND RAPHE NUCLEI}

Previous report has indicated that Pet1 is expressed in the pancreatic islets and shows a restricted expression to the central serotonergic neurons in the brain (Hendricks et al., 1999, 2003; Ohta et al., 2011). We crossed Rosa26-DTR mice with Pet1-Cre mice to generate the Pet1-Cre;Rosa26-DTR (PC/DTR) mice, which led to deplete the Pet1-expressing cells: pancreatic islet cells and central serotonergic neurons in adulthood. The PC/DTR mice have the DTR sequence inserted into the ROSA26 locus, downstream of a loxP-flanked STOP cassette (Buch et al., 2005). Excision of the STOP cassette through Cre recombinase activity therefore renders these cells susceptible to DT-mediated ablation.

We first confirmed the functional Cre recombinase by crossing Pet1-Cre mice with Rosa26-LacZ reporter mice (Soriano, 1999) and assessing $\beta$-gal activity. In the peripheral system of Pet1-Cre;Rosa26-LacZ mice, X-gal-positive staining was only observed in the islets of the pancreas (Figures 2A,B). In our previously published observations (Dai et al., 2008), X-gal staining was detected selectively in the central serotonergic neurons of the raphe nuclei in the brain. We next looked at the expression of Tph2, a specific central serotonergic neuron marker in the brain stem. Along with Nissl staining (Figures 2C,D), Tph2 immunostaining revealed that the central serotonergic neurons were largely

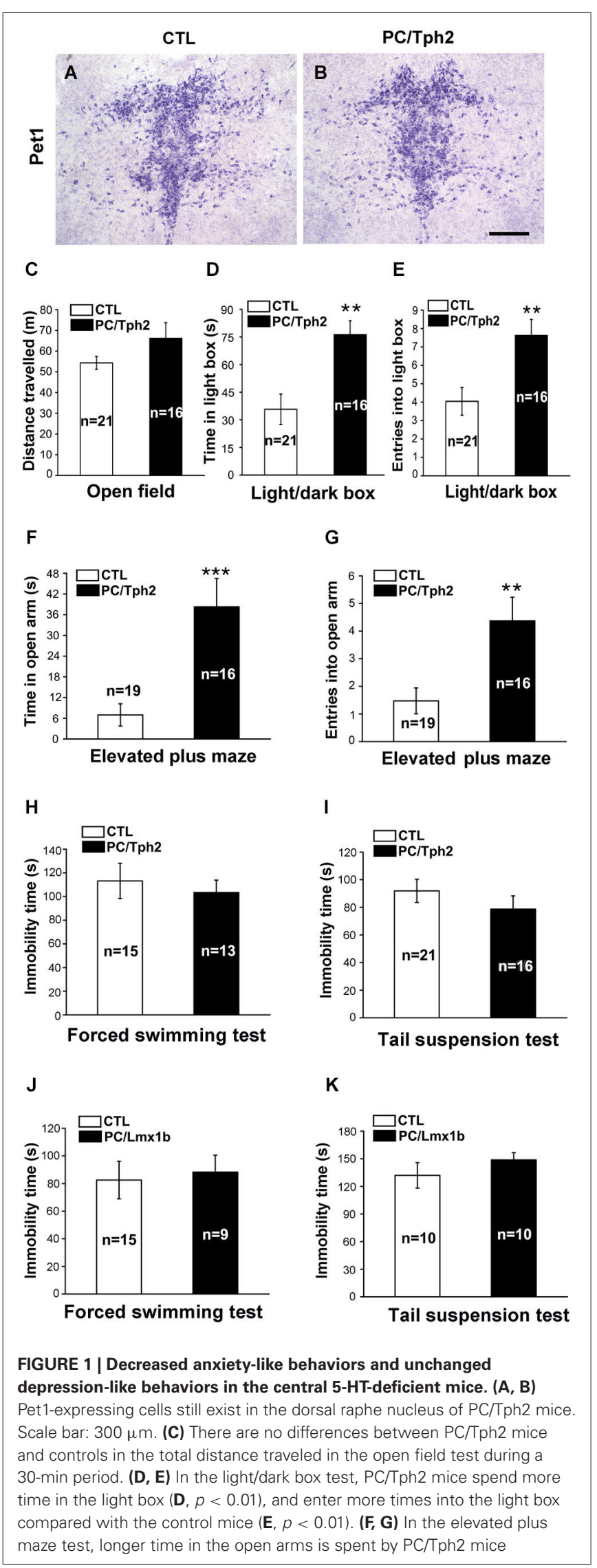




\section{FIGURE 1 | Continued}

$(\mathbf{F}, p<0.001)$, and they also enter more times into the open arms compared with controls (G, $p<0.01)$. (H) Immobility time in the forced swimming test shows no differences between $\mathrm{PC} / \mathrm{Tph} 2$ mice and control mice.

(I) Immobility time in the tail suspension test is not different between PC/Tph2 mice and control mice. (J) Immobility time in the forced swimming test shows no differences between PC/Lm×1b mice and control mice. (K) Immobility time in the tail suspension test shows no differences between PC/Lmx1b mice and control mice. " $n$ " denotes the animal number in figures. CTL: control. All data are expressed as mean \pm SEM. ${ }^{*}$ and *** indicate $p<0.01$ and $p<0.001$

depleted in the raphe nuclei of DT-treated PC/DTR mice compared with controls (Figures 2E-G). Our results here indicate that both the pancreatic islet cells and central serotonergic neurons could be depleted by the systemic administration of DT in adult PC/DTR mice.

\section{DT-TREATED PC/DTR MICE EXHIBIT TYPICAL DIABETES MELLITUS-ASSOCIATED SYMPTOMS}

Functional or physical damage of pancreatic islet cells can result in insulin deficiency, and in turn lead to the onset of diabetes mellitus (DeFronzo et al., 1992). Therefore, we next determined whether selective ablation of islet cells gave rise to diabetic symptoms in the DT-treated PC/DTR mice. We found that despite these mice showed normal body weight (Figure 3A), they exhibited increased food and water intake compared with controls (Figures 3B,C), which are reminiscent of two classic diabetic symptoms: polyphagia and polydipsia. In addition, the litter in the DT-treated PC/DTR mice home cages showed obvious signs of increased urination (Figure 3D). Importantly, blood glucose level after a 3 -h fast was profoundly increased in the DTtreated PC/DTR mice compared with controls (Figure 3E). These results demonstrate that DT-mediated destruction of pancreatic islet cells leads to typical diabetic symptoms in adult PC/DTR mice.

\section{ALTERED ANXIETY- AND DEPRESSION-LIKE BEHAVIORS IN DT-TREATED PC/DTR MICE}

As mentioned previously, diabetes mellitus has been suggested to be an increased risk of developing anxiety and depression. Having observed typical symptoms of diabetes mellitus in our DT-treated PC/DTR mice, which also lacked the central serotonergic neurons, we hypothesized that anxiety- and depression-like behaviors would be changed in these mice.

We first used the open field test to assess the changes in locomotor activity, and found that total traveled distance was not significantly different between the DT-treated PC/DTR and control mice (Figure 4A). The rotarod test was used to evaluate balancing ability, and no a significant difference was detected in the latency to fall between the two groups in three trial tests (Figure 4B). These results show that overall locomotor performance is normal in DT-treated PC/DTR mice.

We used the light/dark box and elevated plus maze tests to evaluate anxiety levels in our DT-treated PC/DTR mice. In the light/dark box test, they spent less time in the light box (Figure 4C) and entered it fewer times compared with the controls (Figure 4D). In the elevated plus maze test, the

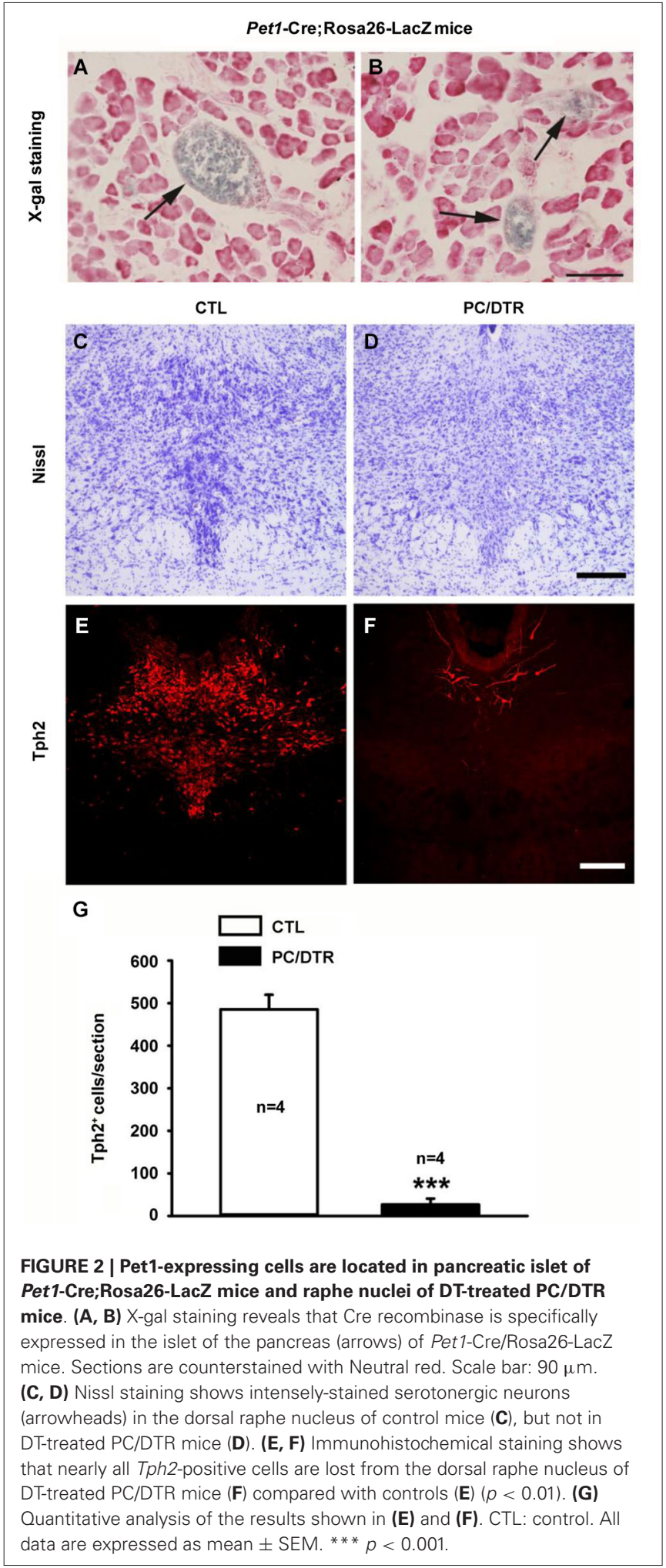

DT-treated PC/DTR mice spent less time exploring the open arms (Figure 4E) and entered into the open arms fewer times compared with control mice (Figure $4 \mathbf{F}$ ). These results suggest that the anxiety levels are increased in the DT-treated PC/DTR mice. 


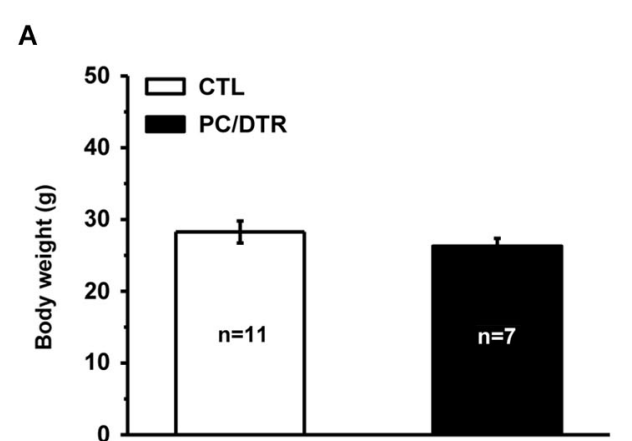

C

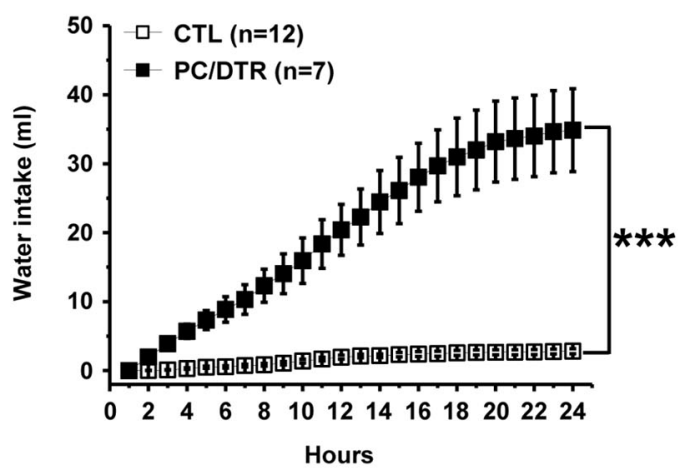

B

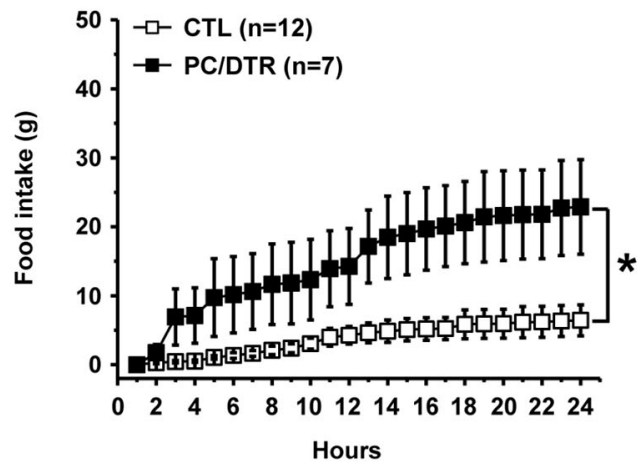

D

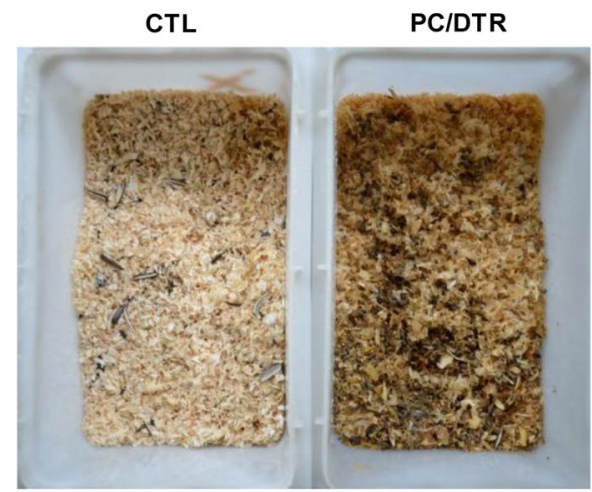

E

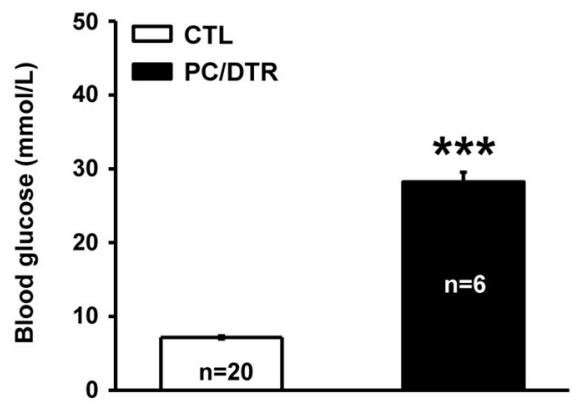

FIGURE 3 | DT-treated PC/DTR mice exhibit typical diabetic symptoms. (A) Average body weight in DT-treated PC/DTR mice is comparable to that of control mice. (B, C) Cumulative food $\left(\mathbf{B}, F_{(1,17)}=7.007, p<0.05\right)$ and water $\left(\mathbf{C}, F_{(1,17)}=46.184, p<0.001\right)$ intake levels over a 24-h period are significantly higher in DT-treated
PC/DTR mice than in controls. (D) DT-treated PC/DTR mice urinate much more than control mice, as revealed by the overall appearance of their litter. (E) Blood glucose levels are markedly increased in DT-treated PC/DTR mice compared with controls $(p<0.01)$. CTL: control. All data are expressed as mean \pm SEM. ${ }^{*} p<0.05,{ }^{* *} p<0.001$.
We next used the forced swimming and tail suspension tests to investigate depression-like behaviors in the PC/DTR mice. Unexpectedly, immobility time was significantly decreased in the forced swimming (Figure 4G) and tail suspension tests (Figure $4 \mathbf{H}$ ) of DT-treated PC/DTR mice, suggesting altered depression-like behaviors. These behavioral phenotypes were not due to any locomotor defects, because the open field and rotarod test results were both comparable to controls.

\section{INCREASED ADULT HIPPOCAMPAL NEUROGENESIS IN DT-TREATED PC/DTR MICE}

Diabetic rodents induced by streptozotocin showed reduced adult hippocampal neurogenesis (Beauquis et al., 2008; Stranahan et al., 2008), while increased neurogenesis and cell proliferation rates were observed in $\mathrm{db} / \mathrm{db}$ mice (Ramos-Rodriguez et al., 2014), which is a widely used genetic mouse model in diabetes research (Sharma et al., 2003). It has been shown that most of clinically used antidepressants (SSRIs being the most common) promote 

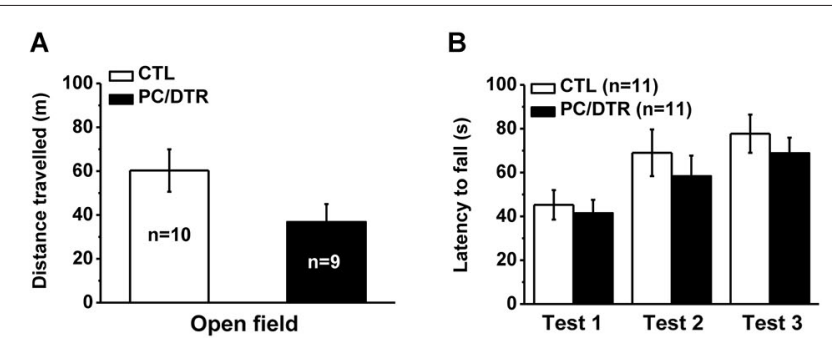

C

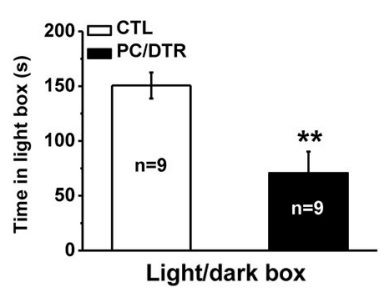

D

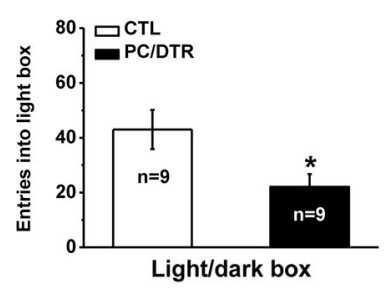

E

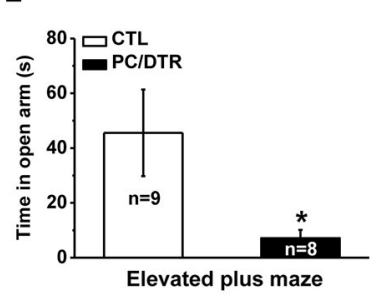

G

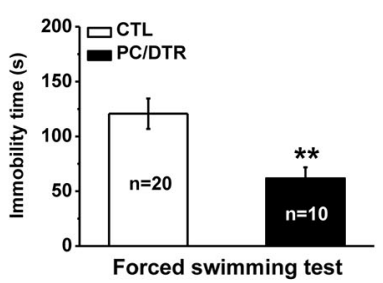

proliferation (van Praag et al., 1999; Kee et al., 2002; Taupin, 2007). Significantly more proliferating cells were observed in SGZ of the dentate gyrus in DT-treated PC/DTR mice compared with controls (Figures 5A-C). We also immunostained for the basic helix-loop-helix transcription factor NeuroD, a marker of differentiating newborn neurons (Lee et al., 1995; Miyata et al., 1999), and observed a pronounced increase in the number of NeuroD-positive cells in DT-treated PC/DTR mice compared with controls (Figures 5D-F). Immature neurons in the SGZ can be visualized also by GFP fluorescence in Pomc-GFP transgenic mice (Overstreet et al., 2004); as expected, more GFP-positive cells were observed in the SGZ of DT-treated PC/DTR/Pomc-GFP mice (Figures 5G-I). Taken together, these results demonstrate that the adult hippocampal neurogenesis is enhanced in DT-treated PC/DTR mice.

\section{DISCUSSION}

In the present study, we found that abnormal behaviors were observed in the two kinds of central 5-HT-deficient mice (PC/Tph2 and PC/Lmx1b). The data from the light/dark box and elevated plus maze tests suggest that the level of anxiety was decreased in these central 5-HT-deficient mice, but was increased in mice with both central 5-HT deficiency and diabetes (DT-treated PC/DTR mice), supporting the idea that the diabetes is a risk factor in developing anxiety. On the other hand, the unchanged immobility time revealed by the forced swimming and tail suspension tests in PC/Tph2 and PC/Lmx1b mice suggest that the central 5-HT deficiency may not be sufficient to induce depression-like behaviors in mice. In addition, we generated a novel transgenic mouse model in which Pet1-expressing cells were deleted in adulthood, and DT-treated PC/DTR mice exhibited typical symptoms of diabetes mellitus, as well as increased anxiety-like but lowered depressionlike behaviors, to which the enhanced hippocampal neurogenesis may contribute. This mouse model (PC/DTR mice) may provide a novel insight to understand and investigate the underlying mechanisms of the clinical comorbidity between diabetes and psychiatric disorders.

Anxiety and depression are known to be associated with central 5-HT deficiency (Coppen, 1967; Naughton et al., 2000), which is supported by the facts that monoaminergic antidepressants attenuate anxiety-like behaviors (Graeff et al., 1996) and also produce beneficial effects in patients with depression (Artigas et al., 1996; Naughton et al., 2000; Blier and Ward, 2003). However, all these antidepressants including SSRIs have a delayed onset of action, although the extracellular 5-HT level is increased several hours after drug intake. In addition, there are approximately one third of depressed patients that do not respond to these antidepressants, and enhancing 5-HT reuptake by the transporter enhancer tianeptine has a similar effect as inhibiting 5-HT reuptake by SSRIs in treating anxiety/depression (Lôo et al., 1992; Lacasse and Leo, 2005; Duman and Aghajanian, 2012). In this investigation, we used two kinds of central 5-HT-deficient mouse lines to explore the level of anxiety- and depressionlike behaviors, and found that the anxiety-like behaviors were decreased but depression-like behaviors were similar to control mice (Figure 1). The depression-like behaviors in Tph2-deficient 


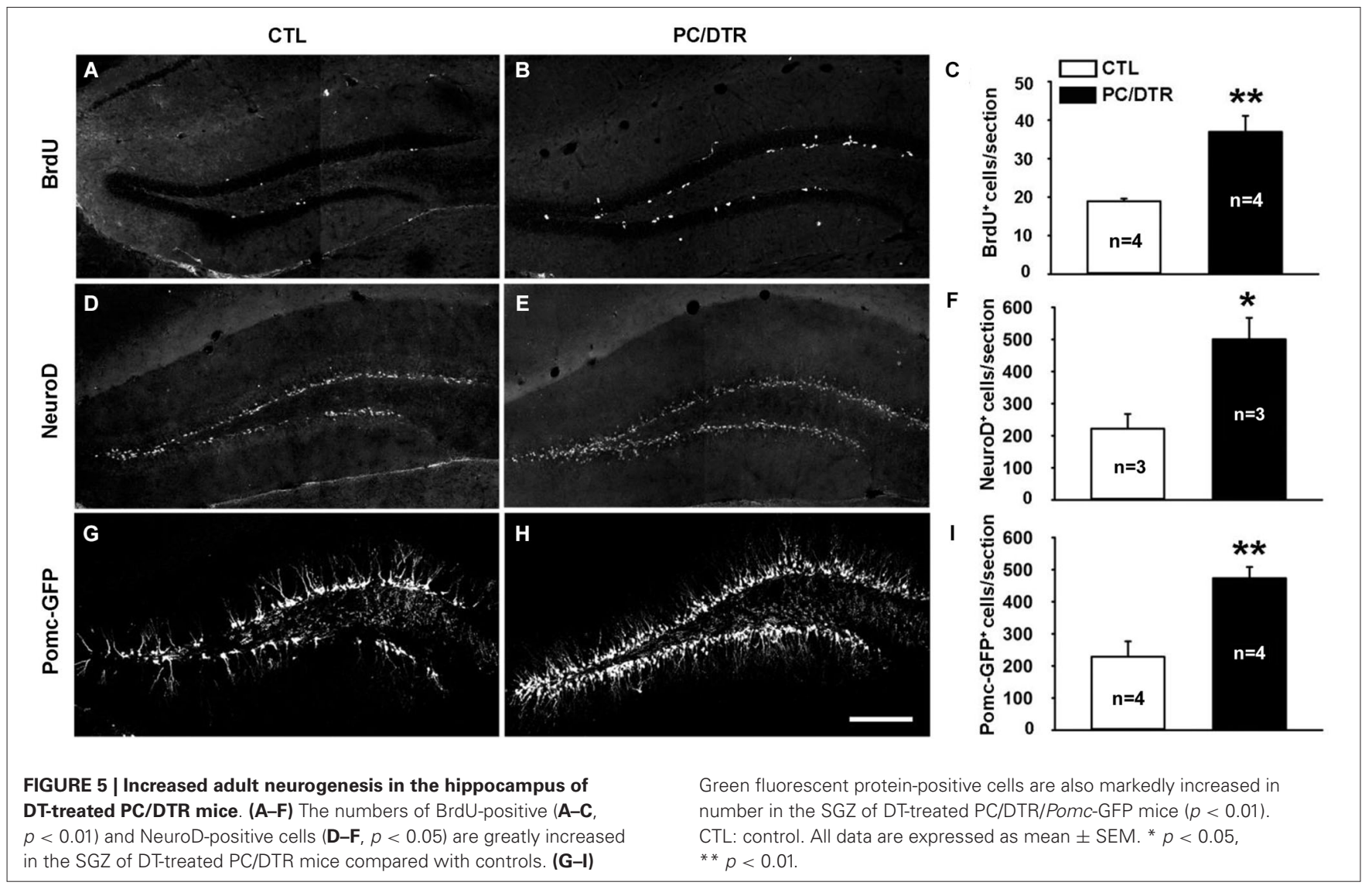

mice is still be a controversial topic: the depression-like behavior shown by tail-suspension test was not changed in Tph 2 knockout mice (Savelieva et al., 2008), while it was increased in Tph2 knockin mice (Belmaker et al., 2008). In addition, it has been reported that the deletion of 5-HT1A receptor in mice increased anxiety, but reduced the immobility in the forced swimming test (Ramboz et al., 1998). Thus, opposite effects in anxiety- and depression-like behaviors by the manipulations of 5-HT system are not unique in our 5-HT-deficient mice. Although it may be argued that the forced swimming and tail suspension tests are behavioral indexes for screening chemicals having potential antidepressant effects in humans, they are also widely used to characterize the depression-like behaviors in rodents (Cryan et al., 2005). A recent finding demonstrates that ketamine, an antagonist of the NMDA receptor, produces rapid, robust and sustained antidepressant effects (Berton and Nestler, 2006; Duman and Aghajanian, 2012). Thus, other mechanisms such as the glutamate and adult hippocampal neurogenesis may play critical roles in depression patients resistant to SSRIs treatments. Nevertheless, our data demonstrate that 5-HT deficiency in the brain may not be sufficient to lead to depression- and anxiety-like behaviors in mice.

As mentioned above, a high prevalence of anxiety/depression is present in patients with diabetes mellitus (Ciechanowski et al., 2000; Anderson et al., 2001). After confirming the loss of Pet1-expressing cells in our DT-treated PC/DTR mice, we assessed them for symptoms of diabetes mellitus. As expected from the loss of islet cells, the mice exhibited several typical symptoms of diabetes mellitus, including polyphagia, polydipsia, polyuria and high blood glucose levels (Figure 3 ). The increased anxiety-like behaviors were observed in DT-treated PC/DTR mice (Figure 4), which is consistent with the conoccurrence of diabetes mellitus and anxiety in clinical observation. On the other hand, the expected increase of the level of depression-like behaviors was not observed. However, the hippocampal neurogenesis was significantly increased in our DT-treated PC/DTR mice (Figures 4, 5). In conventional Tph2 knockout mice (Klempin et al., 2013) and PC/Lmxlb mice (unpublished observation), the adult hippocampal neurogenesis is not changed, but it is enhanced in diabetic $\mathrm{db} / \mathrm{db}$ mice (RamosRodriguez et al., 2014). Thus, it is likely the diabetic complication itself or together with the adult depletion of serotonergic neurons leads to the enhanced hippocampal neurogenesis in DTtreated PC/DTR mice. Previous studies have shown that the enhanced adult hippocampal neurogenesis played critical role in mediating SSRIs-induced antidepressant effect in mice (Malberg et al., 2000; Santarelli et al., 2003). Running wheel training enhances the adult hippocampal neurogenesis in rodents, and this may be a potential mechanism of the therapeutic effects by exercise on alleviating the symptoms of major depression as well as other behavioral defects (Ernstn et al., 2006; Lucassen et al., 2010; Wolf et al., 2011). It is possible that treatments 
(e.g., physical exercise), not limited to SSRIs, could promote adult hippocampal neurogenesis may be beneficial in alleviating depression symptoms.

Interestingly, the patients of wolfram syndrome often suffer from depressive states, and this disease is associated with the juvenile (non-autoimmune) diabetes. As the mouse model of wolfram syndrome, Wfs1-deficient mice displayed increased anxiety but normal depression level (Luuk et al., 2009). The immobility time of Wfs1-deficient mice in the forced swimming and tail suspension tests did not differ from that of wild-type littermates. However, there was augmented response to the administration of antidepressant drugs (imipramine and paroxetine) (Visnapuu et al., 2013). Similarly, our DT-treated PC/DTR mice also showed increased anxiety but a lower level of depression-like behaviors. Therefore, it may be a certain overlap of behavioral phenotypes between the Wfs1-deficient and our DT-treated PC/DTR mice. We supposed that 5 -HT system may have some correlations with Wfs1 gene or wolfram syndrome.

Pet1 is restricted to the serotonergic neurons in the brain, but is not detected in non-serotonergic cells intermingled in the raphe nuclei of the brain stem (Hendricks et al., 1999, 2003). In addition, because wild type mice were used as control, some behavioral alterations observed in the PC/DTR and $\mathrm{PC} / \mathrm{Tph} 2$ mice may be attributed to the possible subtle behavioral and neurobiological abnormalities that may exist in the Pet1-Cre mice, Rosa26-DTR mice and/or Tph2 flox/flox mice. In this study, we took advantage of the Pet1-driven Cre expression to deplete central serotonergic neurons, and this may not directly affect the survival of non-serotonergic neurons, but may affect their function as serotonergic neurons have functional connections with these neurons (Liu et al., 2002). On the other hand, it should be noted that the depletion of serotonergic neurons in DT-treated PC/DTR mice may lead to some degeneration-associated effects such as reactive gliosis, which may be implicated in behavioral alterations observed. Thus, although multiple mouse lines were used to address the relationship between the central 5-HT deficiency and anxiety- or depressionlike behaviors, we could not exclude the possibility that the effects on these behavioral performances are caused indirectly by possible compensations and other unknown changes that are associated with the loss of 5-HT transmitter or serotonergic neurons.

\section{CONCLUSION}

In summary, reduced anxiety-like but unchanged depressionlike behaviors were observed in the two central 5-HT-deficient mice lacking either 5-HT itself or serotonergic neurons. We generated a novel mouse model in which the central serotonergic neurons and pancreatic islet cells were depleted in adulthood. These mice exhibited typical symptoms of diabetes mellitus, increased anxiety-like but a lower level of depression-like behaviors, and increased adult hippocampal neurogenesis. Our results suggest that 5 -HT deficiency may not be sufficient to induce anxiety/depression-like behaviors in mice, and enhanced hippocampal neurogenesis may contribute to the absence of depression-like behaviors in central 5-HT-deficient mice with diabetes mellitus.

\section{ACKNOWLEDGMENTS}

This work was supported by grants from National Basic Research Program of China (2013CB835100 and 2009CB941300), Strategic Priority Research Program of the Chinese Academy of Science (XDB02020200), the National Natural Science Foundation of China $(81221001,31030034,91232724,81200933,81101026$, 31100788, 31100786, U1032605 and U1132602), Fundamental Research Funds for the Central Universities (2013KJ049), and Science and Technology Program of Yunnan Province (2013GA003).

\section{REFERENCES}

Alberti, K. G. M. M., Zimmet, P. Z., and Consultation, W. (1998). Definition, diagnosis and classification of diabetes mellitus and its complications part 1: diagnosis and classification of diabetes mellitus-provisional report of a WHO consultation. Diabet. Med. 15, 539-553. doi: 10.1002/(sici)10969136(199807)15:7<539::aid-dia668>3.0.co;2-s

Anderson, R. J., Freedland, K. E., Clouse, R. E., and Lustman, P. J. (2001). The prevalence of comorbid depression in adults with diabetes - a meta-analysis. Diabetes Care 24, 1069-1078. doi: 10.2337/diacare.24.6.1069

Artigas, F., Romero, L., de Montigny, C., and Blier, P. (1996). Acceleration of the effect of selected antidepressant drugs in major depression by 5-HT1A antagonists. Trends Neurosci. 19, 378-383. doi: 10.1016/s0166-2236(96) 10037-0

Barnes, N. M., and Sharp, T. (1999). A review of central 5-HT receptors and their function. Neuropharmacology 38, 1083-1152. doi: 10.1016/s00283908(99)00010-6

Beauquis, J., Saravia, F., Coulaud, J., Roig, P., Dardenne, M., Homo-Delarche, F., et al. (2008). Prominently decreased hippocampal neurogenesis in a spontaneous model of type 1 diabetes, the nonobese diabetic mouse. Exp. Neurol. 210, 359-367. doi: 10.1016/j.expneurol.2007.11.009

Belmaker, R. H., Agam, G., and Bersudsky, Y. (2008). Role of GSK3beta in behavioral abnormalities induced by serotonin deficiency. Proc. Natl. Acad. Sci. U S A 105:E23. doi: 10.1073/pnas.0801168105

Berton, O., and Nestler, E. (2006). New approaches to antidepressant drug discovery: beyond monoamines. Nat. Rev. Neurosci. 7, 137-151. doi: 10.1038/nrn1846

Blanz, B. J., Renschriemann, B. S., Fritzsigmund, D. I., and Schmidt, M. H. (1993). Iddm is a risk factor for adolescent psychiatric-disorders. Diabetes Care 16, 1579-1587. doi: 10.2337/diacare.16.12.1579

Blier, P., and Ward, N. M. (2003). Is there a role for 5-HT1A agonists in the treatment of depression? Biol. Psychiatry 53, 193-203. doi: 10.1016/s00063223(02)01643-8

Brigitta, B. (2002). Pathophysiology of depression and mechanisms of treatment. Dialogues Clin. Neurosci. 4, 7-20.

Buch, T., Heppner, F. L., Tertilt, C., Heinen, T. J., Kremer, M., Wunderlich, F. T., et al. (2005). A Cre-inducible diphtheria toxin receptor mediates cell lineage ablation after toxin administration. Nat. Methods 2, 419-426. doi: 10.1038/ nmeth762

Butler, A. E., Janson, J., Bonner-Weir, S., Ritzel, R., Rizza, R. A., and Butler, P. C. (2003). Beta-cell deficit and increased beta-cell apoptosis in humans with type 2 diabetes. Diabetes 52, 102-110. doi: 10.2337/diabetes.52.1.102

Castagne, V., Moser, P., Roux, S., Porsolt, R. D. (2011). "Rodent models of depression: forced swim and tail suspension behavioral despair tests in rats and mice," in Current Protocols in Neuroscience, ed J. N. Crawley (Hoboken, NJ: Wiley Press), Chapter 8, Unit 8 10A, 55:8.10A.1-8.10A.14. doi: 10.1002/0471142301

Ciechanowski, P. S., Katon, W. J., and Russo, J. E. (2000). Depression and diabetesimpact of depression symptoms on adherence, function, costs. Arch. Intern. Med. 160, 3278-3285. doi: 10.1001/archinte.160.21.3278

Cooke, D. W., and Plotnick, L. (2008). Type 1 diabetes mellitus in pediatrics. Pediatr. Rev. 29, 374-385. doi: 10.1542/pir.29-11-374

Coppen, A. (1967). The biochemistry of affective disorders. Br. J. Psychiatry 113 1237-1264. doi: 10.1192/bjp.113.504.1237

Cryan, J. F., Mombereau, C., and Vassout, A. (2005). The tail suspension test as a model for assessing antidepressant activity: review of pharmacological and genetic studies in mice. Neurosci. Biobehav. Rev. 29, 571-625. doi: 10.1016/j. neubiorev.2005.03.009 
Dai, J.-X., Han, H.-L., Tian, M., Cao, J., Xiu, J.-B., Song, N.-N., et al. (2008). Enhanced contextual fear memory in central serotonin-deficient mice. Proc. Natl. Acad. Sci. U S A 105, 11981-11986. doi: 10.1073/pnas.0801329105

David, D. J. P., Renard, C. E., Jolliet, P., Hascoët, M., and Bourin, M. (2003). Antidepressant-like effects in various mice strains in the forced swimming test. Psychopharmacology (Berl) 166, 373-382. doi: 10.1007/s00213-002-1335-4

DeFronzo, R. A., Bonadonna, R. C., and Ferrannini, E. (1992). Pathogenesis of niddm—a balanced overview. Diabetes Care 15, 318-368. doi: 10.2337/diacare. 15.3.318

Ding, Y.-Q., Marklund, U., Yuan, W., Yin, J., Wegman, L., Ericson, J., et al. (2003). Lmxlb is essential for the development of serotonergic neurons. Nat. Neurosci. 6, 933-938. doi: 10.1038/nn1104

Duman, R. S., and Aghajanian, G. K. (2012). Synaptic dysfunction in depression: potential therapeutic targets. Science 338, 68-72. doi: 10.1126/science.1222939

Duman, R. S., and Voleti, B. (2012). Signaling pathways underlying the pathophysiology and treatment of depression: novel mechanisms for rapid-acting agents. Trends Neurosci. 35, 47-56. doi: 10.1016/j.tins.2011.11.004

Ernstn, C., Olson, A., Pinel, J., Lam, R., and Christie, B. (2006). Antidepressant effects of exercise: evidence for an adult-neurogenesis hypothesis? J. Psychiatry Neurosci. 31, 84-92.

Graeff, F. G., Guimarães, F. S., De Andrade, T. G., and Deakin, J. F. (1996). Role of 5-HT in stress, anxiety and depression. Pharmacol. Biochem. Behav. 54, 129-141. doi: 10.1016/0091-3057(95)02135-3

Hendricks, T., Francis, N., Fyodorov, D., and Deneris, E. S. (1999). The ETS domain factor Pet-1 is an early and precise marker of central serotonin neurons and interacts with a conserved element in serotonergic genes. J. Neurosci. 19, 1034810356.

Hendricks, T. J., Fyodorov, D. V., Wegman, L. J., Lelutiu, N. B., Pehek, E. A., Yamamoto, B., et al. (2003). Pet-1 ETS gene plays a critical role in 5-HT neuron development and is required for normal anxiety-like and aggressive behavior. Neuron 37, 233-247. doi: 10.1016/s0896-6273(02)01167-4

Kee, N., Sivalingam, S., Boonstra, R., and Wojtowicz, J. M. (2002). The utility of Ki67 and BrdU as proliferative markers of adult neurogenesis. J. Neurosci. Methods 115, 97-105. doi: 10.1016/s0165-0270(02)00007-9

Klempin, F., Beis, D., Mosienko, V., Kempermann, G., Bader, M., and Alenina, N. (2013). Serotonin is required for exercise-induced adult hippocampal neurogenesis. J. Neurosci. 33, 8270-8275. doi: 10.1523/JNEUROSCI.5855-12.2013

Kriegebaum, C., Song, N.-N., Gutknecht, L., Huang, Y., Schmitt, A., Reif, A., et al. (2010). Brain-specific conditional and time-specific inducible Tph2 knockout mice possess normal serotonergic gene expression in the absence of serotonin during adult life. Neurochem. Int. 57, 512-517. doi: 10.1016/j.neuint.2010. 06.015

Lacasse, J. R., and Leo, J. (2005). Serotonin and depression: a disconnect between the advertisements and the scientific literature. PLos Med. 2:e392. doi: 10. 1371/journal.pmed.0020392

Lee, J. E., Hollenberg, S. M., Snider, L., Turner, D. L., Lipnick, N., and Weintraub, H. (1995). Conversion of Xenopus ectoderm into neurons by NeuroD, a basic helix-loop-helix protein. Science 268, 836-844. doi: 10.1126/science.7754368

Lenoir, O., Flosseau, K., Ma, F. X., Blondeau, B., Mai, A., Bassel-Duby, R., et al. (2011). Specific control of pancreatic endocrine beta- and delta-cell mass by class IIa histone deacetylases HDAC4, HDAC5 and HDAC9. Diabetes 60, 28612871. doi: 10.2337/db11-0440

Leonardo, E. D., and Hen, R. (2006). Genetics of affective and anxiety disorders. Annu. Rev. Psychol. 57, 117-137. doi: 10.1146/annurev.psych.57.102904.190118

Lister, R. G. (1987). The use of a plus-maze to measure anxiety in the mouse. Psychopharmacology (Berl) 92, 180-185. doi: 10.1007/bf00177912

Liu, R., Ding, Y., and Aghajanian, G. K. (2002). Neurokinins activate local glutamatergic inputs to serotonergic neurons of the dorsal raphe nucleus. Neuropsychopharmacology 27, 329-340. doi: 10.1016/s0893-133x(02)00305-6

Lôo, H., Ganry, H., Dufour, H., Guelfi, J., Malka, R., Olié, J., et al. (1992). Longterm use of tianeptine in 380 depressed patients. Br. J. Psychiatry Suppl. 15, 61-65.

Lucassen, P. J., Meerlo, P., Naylor, A. S., van Dam, A. M., Dayer, A. G., Fuchs, E., et al. (2010). Regulation of adult neurogenesis by stress, sleep disruption, exercise and inflammation: implications for depression and antidepressant action. Eur. Neuropsychopharmacol. 20, 1-17. doi: 10.1016/j.euroneuro.2009.08. 003

Luuk, H., Plaas, M., Raud, S., Innos, J., Sütt, S., Lasner, H., et al. (2009). Wfs1-deficient mice display impaired behavioural adaptation in stressful environment. Behav. Brain Res. 198, 334-345. doi: 10.1016/j.bbr.2008. 11.007

Malberg, J. E., Eisch, A. J., Nestler, E. J., and Duman, R. S. (2000). Chronic antidepressant treatment increases neurogenesis in adult rat hippocampus. $J$. Neurosci. 20, 9104-9110.

Miyata, T., Maeda, T., and Lee, J. E. (1999). NeuroD is required for differentiation of the granule cells in the cerebellum and hippocampus. Genes Dev. 13, 1647-1652. doi: 10.1101/gad.13.13.1647

Naughton, M., Mulrooney, J., and Leonard, B. (2000). A review of the role of serotonin receptors in psychiatric disorders. Hum. Psychopharmacol. 15, 397415. doi: 10.1002/1099-1077(200008)15:6<397::aid-hup212>3.3.co;2-c

Nestler, E. J., Gould, E., Manji, H., Buncan, M., Duman, R. S., Gershenfeld, H. K., et al. (2002). Preclinical models: status of basic research in depression. Biol. Psychiatry 52, 503-528. doi: 10.1016/s0006-3223(02)01405-1

Ohta, Y., Kosaka, Y., Kishimoto, N., Wang, J., Smith, S. B., Honig, G., et al. (2011). Convergence of the insulin and serotonin programs in the pancreatic $\beta$-cell. Diabetes 60, 3208-3216. doi: 10.2337/db10-1192

Overstreet, L. S., Hentges, S. T., Bumaschny, V. F., de Souza, F. S. J., Smart, J. L., Santangelo, A. M., et al. (2004). A transgenic marker for newly born granule cells in dentate gyrus. J. Neurosci. 24, 3251-3259. doi: 10.1523/jneurosci.517303.2004

Popkin, M. K., Callies, A. L., Lentz, R. D., Colon, E. A., and Sutherland, D. E. (1988). Prevalence of major depression, simple phobia and other psychiatric-disorders in patients with long-standing type-I diabetes-mellitus. Arch. Gen. Psychiatry 45, 64-68. doi: 10.1001/archpsyc.1988.01800250078010

Porsolt, R. D. (2000). Animal models of depression: utility for transgenic research. Rev. Neurosci. 11, 53-58.

Porsolt, R. D., Le Pichon, M., and Jalfre, M. (1977). Depression: a new animal model sensitive to antidepressant treatments. Nature 266, 730-732. doi: 10. $1038 / 266730 \mathrm{a} 0$

Ramboz, S., Oosting, R., Amara, D. A., Kung, H. F., Blier, P., Mendelsohn, M., et al. (1998). Serotonin receptor 1A knockout: an animal model of anxiety-related disorder. Proc. Natl. Acad. Sci. U S A 95, 14476-14481. doi: 10.1073/pnas.95.24. 14476

Ramos-Rodriguez, J. J., Molina-Gil, S., Ortiz-Barajas, O., Jimenez-Palomares, M., Perdomo, G., Cozar-Castellano, I., et al. (2014). Central proliferation and neurogenesis is impaired in type 2 diabetes and prediabetes animal models. PLoS One 9:e89229. doi: 10.1371/journal.pone.0089229

Santarelli, L., Saxe, M., Gross, C., Surget, A., Battaglia, F., Dulawa, S., et al. (2003). Requirement of hippocampal neurogenesis for the behavioral effects of antidepressants. Science 301, 805-809. doi: 10.1126/science.1083328

Savelieva, K. V., Zhao, S., Pogorelov, V. M., Rajan, I., Yang, Q., Cullinan, E., et al. (2008). Genetic disruption of both tryptophan hydroxylase genes dramatically reduces serotonin and affects behavior in models sensitive to antidepressants. PLoS One 3:e3301. doi: 10.1371/journal.pone.0003301

Sharma, K., McCue, P., and Dunn, S. R. (2003). Diabetic kidney disease in the db/db mouse. Am. J. Physiol. Renal Physiol. 284, F1138-F1144. doi: 10.1152/ ajprenal.00315.2002

Song, N. N., Xiu, J. B., Huang, Y., Chen, J. Y., Zhang, L., Gutknecht, L., et al. (2011). Adult raphe-specific deletion of $1 \mathrm{mx} 1 \mathrm{~b}$ leads to central serotonin deficiency. PLos One 6:e15998. doi: 10.1371/journal.pone.0015998

Soriano, P. (1999). Generalized lacZ expression with the ROSA26 Cre reporter strain. Nat. Genet. 21, 70-71. doi: 10.1038/5007

Steru, L., Chermat, R., Thierry, B., and Simon, P. (1985). The tail suspension test: a new method for screening antidepressants in mice. Psychopharmacology (Berl) 85, 367-370. doi: 10.1007/bf00428203

Stranahan, A. M., Arumugam, T. V., Cutler, R. G., Lee, K., Egan, J. M., and Mattson, M. P. (2008). Diabetes impairs hippocampal function through glucocorticoidmediated effects on new and mature neurons. Nat. Neurosci. 11, 309-317. doi: $10.1038 / \mathrm{nn} 2055$

Taupin, P. (2007). BrdU immunohistochemistry for studying adult neurogenesis: paradigms, pitfalls, limitations and validation. Brain Res. Rev. 53, 198-214. doi: 10.1016/j.brainresrev.2006.08.002

Tian, M., Mao, R. R., Wang, L. P., Zhou, Q. X., Cao, J., and Xu, L. (2011). Interaction between behavioral despair and addictive behaviors in rats. Physiol. Behav. 102, 7-12. doi: 10.1016/j.physbeh.2010.10.002

van Praag, H., Kempermann, G., and Gage, F. H. (1999). Running increases cell proliferation and neurogenesis in the adult mouse dentate gyrus. Nat. Neurosci. 2, 266-270. doi: 10.1038/6368 
Visnapuu, T., Raud, S., Loomets, M., Reimets, R., Sütt, S., Luuk, H., et al. (2013). Wfs1-deficient mice display altered function of serotonergic system and increased behavioral response to antidepressants. Front. Neurosci. 7:132. doi: 10. 3389/fnins.2013.00132

Weisstaub, N. V., Zhou, M. M., Lira, A., Lambe, E., González-Maeso, J., Hornung, J. P., et al. (2006). Cortical 5-HT2A receptor signaling modulates anxiety-like behaviors in mice. Science 313, 536-540. doi: 10.1126/science.1123432

Wild, S., Roglic, G., Green, A., Sicree, R., and King, H. (2004). Global prevalence of diabetes: estimates for the year 2000 and projections for 2030. Diabetes Care 27, 1047-1053. doi: 10.2337/diacare.27.5.1047

Wolf, S. A., Melnik, A., and Kempermann, G. (2011). Physical exercise increases adult neurogenesis and telomerase activity and improves behavioral deficits in a mouse model of schizophrenia. Brain Behav. Immun. 25, 971-980. doi: 10. 1016/j.bbi.2010.10.014

Zhang, X., Beaulieu, J. M., Sotnikova, T. D., Gainetdinov, R. R., and Caron, M. G. (2004). Tryptophan hydroxylase-2 controls brain serotonin synthesis. Science 305:217. doi: 10.1126/science.1097540
Conflict of Interest Statement: The authors declare that the research was conducted in the absence of any commercial or financial relationships that could be construed as a potential conflict of interest.

Received: 23 July 2014; accepted: 01 September 2014; published online: 23 September 2014.

Citation: Jia Y-F, Song N-N, Mao R-R, Li J-N, Zhang Q, Huang Y, Zhang L, Han $H$-L, Ding Y-Q and Xu L (2014) Abnormal anxiety-and depression-like behaviors in mice lacking both central serotonergic neurons and pancreatic islet cells. Front. Behav. Neurosci. 8:325. doi: 10.3389/fnbeh.2014.00325

This article was submitted to the journal Frontiers in Behavioral Neuroscience. Copyright (C) 2014 Jia, Song, Mao, Li, Zhang, Huang, Zhang, Han, Ding and Xu. This is an open-access article distributed under the terms of the Creative Commons Attribution License (CC BY). The use, distribution or reproduction in other forums is permitted, provided the original author (s) or licensor are credited and that the original publication in this journal is cited, in accordance with accepted academic practice. No use, distribution or reproduction is permitted which does not comply with these terms. 